DOI: $10.17805 /$ zpu.2016.2.16

\title{
Модели коммуникации власти и общества в механизме публичного управления современной Японии
}

\author{
P. T. МУХАEB
}

(МОСКОВСКИЙ ГУМАНИТАРНЫЙ УНИВЕРСИТЕТ)

В статье раскрывается проблема когнитивных основ формирования и функционирования коммуникативных практик в механизме публичного управления незападных обществ на примере Японии.

Анализируются легальные и теневые каналы участия различных заинтересованных групп в распределении «общественного блага» с использованием институтов публичной власти. Все коммуникативные практики в сфере публичных услуг включены в особый образец социальных и политических диспозиций, которые в решающей мере определяют эффективность политической системы и ее институтов в разных странах. Диспозиции и паттерны поведения объясняют, почему универсальные институты и практики демократического правления по-разному работают в разных культурных средах. 
Структура институтов публичного управления в Японии аналогична парламентским моделям, распространенным на Западе, но адаптированным к местной культурной среде. По этой причине современная система политической коммуникации Японии представляет собой синтез традиционных начал и институциональных новаций. Благодаря развитой культурной традиции и ориентации элит на реализацию национальных интересов система публичного управления Японии чрезвычайно восприимчива к внешним изменениям и способна трансформироваться. Провозглашая свою исконную, глубинную связь с религиозно-философской и этической традицией, японцы, тем не менее, всегда проявляли большую гибкость и готовность принять иноземные элементы, если те открывали новые возможности для процветания страны и повышали легитимность публичной власти. Для лучшего восприятия и адаптации к повседневной жизни эти новшества были облечены в национально-культурные формы. Усвоенные таким образом зарубежные практики становились привычно японскими, что означало «вестернизацию» содержания религиозно-философской традиции, формирование на этой основе обновленной традиции, переосмысленной в соответствии с требованиями времени. В этом смысле система государственного управления Японии носит инновационный характер, она постоянно совершенствовалась путем заимствования институтов и процедур западного (континентального и англо-американского) государственного менеджмента.

Ключевые слова: власть; политика; группы интересов; политические практики; демократия; Япония; политическая культура Японии

\section{BВЕАЕНИЕ}

$\mathrm{T}$ еоретическая и практическая значимость рассматриваемой проблемы обусловлена поисками эффективных моделей публичного управления в условиях нелинейной динамики. Процессы глобализации, условность национальных границ, неконтролируемая миграция, растущее разнообразие потребностей вызвали необходимость критического переосмысления механизмов и каналов коммуникации власти и общества в условиях столь быстрых социальных, экономических, политических, культурных сАвигов.

Очевидно, что современное общество представляет собой динамично меняющуюся мозаику разнообразных устойчивых и изменчивых форм коммуникаций, направленных на реализацию как повседневных, так и общезначимых интересов. Складывающиеся коммуникативные практики как представления и образцы повседневных взаимодействий во времени и пространстве обычно задают динамические модели поведения индивидов. На их основе складываются социальные институты, являющиеся ответом на запросы различных групп и выступающие формами артикуляции, агрегации и имплементации их интересов. В одних обществах эти формы представительства и продвижения интересов институционализированы и отражают подвижный набор предпочтений, в других - адаптация общества к меняющейся социальной реальности происходит через сохранение привычных практик, традиций и поведенческих паттернов. Причем в условиях глобализации и нарастания социального и культурного многообразия современных обществ эта стратегия адаптации оказывается не менее эффективной. При этом западная плюралистическая политическая система, считавшаяся прежде эффективной, оказалась не в состоянии адекватно выразить растущее многообразие интересов. Это стало причиной конфликта элит и масс в развитых странах Запада. Универсальные институты (государство, парламенты, партии, церковь, СМИ), через которые гражданское общество на Западе адресовало свои запросы власти, переживают кризис. Это актуализирует интерес к альтернативным моделям коммуникации власти и общества, которые сложились в незападных обществах. Рассмотрим эту тему применительно к Японии. 


\section{ПУБАИЧНОЕ УПРАВАЕНИЕ КАК СПОСОБ КОНСТРУИРОВАНИЯ}

УНИВЕРСААЬНЫХ СОЦИААЬНЫХ ПРАКТИК

Механизмом конструирования универсальных социальных практик выступает политика и ее главный инструмент - государство. Государство представляет собой особую организацию публичной власти, назначение которой состоит в реализации общесоциальных функций: установление общественного и правового порядка, обеспечение «общего блага», единства, безопасности и жизнедеятельности общества, гарантиях прав и свобод личности и т. А. Специфика упорядочивающего воздействия государства связана с наличием у него монополии устанавливать общеобязательные властные предписания (нормы права) и монополии на легитимное насилие, осуществляемое с помощью первичной «клеточки» государственного механизма - государственного органа (например, парламента, правительства, суда).

Понять механизм конструирования социальных практик можно в контексте культурных и научных традиций того общества и той исторической эпохи, в которой они создавались. Формы социальной и политической организации конкретного общества всякий раз задавались доминирующей системой мышления, которую М. Фуко назвал эnистемой (Фуко, 2002: 67). Конструирование социальных практик и институтов в конкретный период происходит в процессе коммуникации акторов под воздействием доминирующих систем мышления, интерпретирующих их действия. Политическая коммуникация представляет собой сложный процесс, организующий и структурирующий социокультурное пространство. Специфика политической коммуникации состоит в формировании универсальных дискурсов, задающих смыслы и модели поведения, формирующих политические практики и институты, которые гарантируют политический порядок.

На Западе выделение политики в особую сферу социальных взаимодействий в эпоху модерна (XVIII-XX вв.) означало появление в лице государства-нации и его политической системы механизма коллективного целеполагания и воспроизводства общих моделей поведения и культурных значений, обязательных для всех граждан государства. С той поры любой социальный порядок в западных странах стал опираться на универсальные правила и нормы, модели поведения, принятые в том обществе и закрепленные в законодательстве. Системой координат, организующей и упорядочивающей самоопределение индивида во взаимодействиях на макроуровне, является гражданская идентичность в рамках государства-нации.

В незападных обществах политика не дифференцировалась в особую сферу, способную обеспечить интеграцию общества на основе универсальных правил. Институционализация политических практик в них происходила на основе партикулярных правил: принадлежности индивида к локальной группе (клану, сословию, классу, конфессии, профессии и т. А.), а не к государству-нации. В этих странах сложились партикулярные практики, ориентированные на восприятие закрытых сегрегированных единиц. В силу слабости государства-нации ни один центр силы не смог сформулировать общенациональные проблемы, элиминировать их на другие центры власти и использовать для их продвижения не локальные, а институционализированные универсальные практики.

Аля понимания механизмов формирования личностных и корпоративных идентичностей в публичной сфере современного общества важным представляется понимание того, как интерпретируется мир политического. В науке существуют два альтернативных мнения по поводу природы мира политики: одни считают ее сферой дости- 
жения «общего блага», а другие - полем реализации частных целей с использованием институтов публичной власти.

Аолгое время в науке преобладали директивные трактовки политики, которые рассматривали ее как механизм волевого распределения «общественного блага» (ценностей, ресурсов, статусов) в процессе взаимодействия государства (его органов) и общества (в лице партий, групп интересов, институтов). В процессе коммуникации власти и общества происходит а) артикуляция групповых и индивидуальных интересов; б) агрегирование их в общую программу или позицию; в) выработка политического курса, учитывающего общественные запросы; г) реализация принятых решений; А) контроль за их исполнением. Согласно этому подходу политика рассматривается как функционально-ролевое взаимодействие носителей политической власти (элиты, чиновники) и граждан, в котором действия «властвующего» и «подвластного» регламентируются общепринятыми моделями поведения, институционально закрепленными в праве. В свою очередь, направленность этих политических взаимодействий, их содержание и формы заданы системой ценностей и диспозиций агентов власти, разделяемой ими картиной мира, актуализированной в доминирующем типе политической культуры. Воспроизводство универсальных политических практик и институтов, которые обеспечивают политический порядок в обществе, происходит благодаря наличию у граждан однотипных представлений, смысловых значений, позволяющих им договориться о единых правилах, стандартах и моделях политического поведения. Соблюдение же универсальных норм поведения, кроме общих смыслов, опирается на монополию легитимного насилия со стороны государства, признаваемую обществом.

На рубеже XX-XXI вв. директивную интерпретацию политики сменила рыночная парадигма, которая понимала политику как рынок публичных услуг, где происходит обмен ресурсами и благами. Новая парадигма была сформирована путем перенесения идей и принципов экономической теории общественного выбора Вирджинской школы (Э. Аткинсон, Аж. Бреннан, Аж. Бьюкенен, У. Нисканен, М. Олсон, Г. Таллок, Р. Толлисон) на политику. Согласно ей поведение гражданина на политическом рынке рационально әгоистично и аналогично поведению потребителя на экономическом рынке: везде он стремится максимизировать свою прибыль и минимизировать убытки. Основное различие между экономическим и политическим рынками состоит в характере благ и механизме реализации общественных запросов.

Один из основателей теории общественного выбора (public chose) Аж. Бьюкенен писал: «Политика - есть сложная система обмена между индивидами, в которой последние коллективно стремятся к достижению своих частных целей, так как не могут реализовать их путем обычного рыночного обмена. Здесь нет других интересов, кроме индивидуальных. На рынке люди меняют яблоки на апельсины, а в политике - соглашаются платить налоги в обмен на блага, необходимые всем и каждому: от местной пожарной охраны до суда» (Бьюкенен, 1994: 108). Следовательно, индивиды, независимо от занимаемого положения - государственный служащий или обыватель, во всем руководствуются интересами личной выгоды. В логике рыночного поведения государство не является провайдером «общественного блага» и не выступает механизмом реализации общезначимых потребностей. Государство - это особый рынок: на нем люди конкурируют за доступ к общественным благам, места во властной иерархии, статусы и репутации. Преследуя цели максимизации личной выгоды, индивиды стремятся легально использовать органы государственной власти - 
представительные, исполнительные и судебные - к своей личной выгоде. Согласие на этом рынке - результат обмена ресурсов на основе правил, закрепленных в Конституции.

В плюралистических системах западного гражданского общества артикуляция общественных запросов осуществляется через формализованные каналы коммуникации власти и общества: партийные системы, выборы, независимые СМИ позволяют транслировать общественные запросы институтам государства, контролировать процесс принятия решений. Каков механизм встраивания интересов общностей, групп и корпораций в политическую систему незападных общества, к которым относится японское общество, где преобладают латентные каналы коммуникации?

Аля выявления технологий формирования стратегий и практик имплементации групповых и частных интересов в публичной сфере важно понимание специфики традиционного японского общества, иерархии факторов, обусловливающих своеобразие политических коммуникации власти и общества.

\section{ЯПОНСКИЙ СТИАЬ ПУБАИЧНОГО УПРАВАЕНИЯ: \\ МЕХАНИЗМ ГАРМОНИЗАЦИИ ПАРТИКУАЯРНЫХ ПРАКТИК}

Несмотря на инвазию западных институтов артикуляции интересов (парламента, партий, выборов) в структуру японского общества, оно по-прежнему остается традиционным и функционирует на иных принципах, чем западное. Японское общество часто называют «общестъо-паутина» (или «деревенским обществом»), где все его члены жестко взаимозависимы и между ними устанавливается строгая иерархия моральных и социальных обязательств как по вертикали, так и по горизонтали. Коммуникативные практики в «обществе-паутине» носят преимущественно вертикальный характер и складываются на основе культурного плюрализма - сосуществования в рамках одного государства замкнутых социальных групп, культурных общностей, осознающих свою этническую, клановую, кастовую, религиозную, языковую особенность. Глубокое осознание индивидом своей принадлежности к определенному сообществу приводит к четкому оформлению сплоченности вертикальных сообществ. В отличие от западного плюрализма, который стремится к полной интеграции всех сообществ на едином культурном основании, японский плюрализм признает самобытность каждой общности, сохраняет все многообразие культур, обычаев, стилей жизни, вкусов, заданных разными ментальными кодами.

Ментальные коды феномена, который принято называть японским духом (нихонтэки кэйэй), составляют синкретическое соединение важнейших элементов синтоизма и буддизма, встроенных в морально-этическую доктрину конфуцианства. Ментальный синтез конфуцианства, синтоизма и буддизма стал мировоззренческой основой культуры современной Японии, оказал решающее влияние на формирование моделей коммуникации в системе «власть - общество - индивид», определил природу социальных институтов и методов управления.

Роль фактора, интегрирующего японское общество, выполняет синтоизм - национальная религия, обращенная только к японцам. Он основан на почитании культа предков и сил природы, закрепляет «божественное предназначение японской нации», ее эмоциональное единство. Слово «синто» состоит из двух иероглифов: «син» (божество) и «то» (путь). Аословно синто переводится как «путь богов». Синтоизм был официальной государственной религией в VII-IX вв., а затем в 1868-1882 гг. Согласно синтоистскому вероучению люди произошли от ками (божеств, духов природы, 
божественных предков), живут с ними в одном мире. Ками незримо присутствуют везде, продолжают жить во всех японцах, наделяют их человеческими добродетелями. Живым воплощением богини Аматэрасу - богини Солнца, верховного божества, является император. Аматэрасу - прародительница и покровительница императорского дома, гарант непрерывности императорской династии. С синтоизмом связано возникновение государства в Японии, которое основано на культе императорской династии. Согласно этому учению Япония представляет собой государство-семью, в котором отношения между императором и подданными основаны на взаимной заботе и учтивости, преданности правителю и сыновней почтительности. Высокое предназначение Японии, ее превосходство над другими странами определяют божественный дух японского народа, его особые качества,

В отличие от синтоизма буддизм провозглашает приоритет индивидуалистическо20 начала, учит достижению гармонии посредством медитации, воспитывает склонность к компромиссам, развивает способность гармонично вписываться в окружающий культурный ландшафт. Если в синтоизме акцент сделан на коллективистские ценности, смирение, то в буддизме утверждается, что человек своими усилиями может сделать себя благородным существом. Максима буддизма: поступая хорошо, вкушаешь радость и умиротворенность, поступая плохо, пожинаешь болезни, бедность, унижения. Активное начало в буддизме связано с тем, что бытие человека, его жизнь меняется под влиянием его поступков и правильных мыслей. Человек является творцом своей судьбы, поскольку только неустанной работой над собой, стремлением к самосовершенствованию можно преодолеть страдания.

Решающее влияние на повседневную жизнь японцев оказало конфуицанство в нем сформулированы базисные принципы их философии и поведения. По Конфуцию, главным фактором социального порядка выступает патриархально-клановая структура общества, в которой предназначение личности определяется соображениями ее социальной полезности и местом в иерархии семейно-родственных связей. Тем самым утверждается абсолютный приоритет интересов общества (семьи, клана, государства) над интересами личности и преодолевается антагонизм «общего» и «частного ». Возвышение личности возможно лишь благодаря поддержке со стороны группы (семьи), которая несет ответственность за ее благополучие.

Суть доктрины «идеального общества» Конфуция сводится к набору принципов добродетельного поведения:

1) порядок в обществе основан на неравенстве между людьми и строгой социальной иерархии, где все коммуникации выстраиваются вертикально по линии: «правитель - подданный, отец - сын, старший брат - младший брат, муж - жена, старший друг - младший друг». Игнорирование этих типов отношений является причиной беспорядков и ведет к распаду государства;

2) добродетельное отношение к другим. Каждый должен сохранять свое лицо. Прочность социального порядка опирается не столько на социальное происхождение, сколько на нравственные качества людей следовать чувству долга и справедливости. Благородные мужи (правители) возлагают на себя моральные обязательства защищать тех, кто проявляет к ним доброту, демонстрирует им свое повиновение и преданность;

3) семья - основа любого общества, поскольку все мы члены какой-нибудь группы, где каждый заботиться о благополучии всех;

4) образование и упорный труд должны вознаграждаться; 
5) принцип золотой середины. Умеренность во всем: старайтесь не потакать себе, избегайте крайностей, сохраняйте спокойствие, будьте бережливы.

Культурный плюрализм как устойчивое осознание своей принадлежности к определенному сообществу (клану, профессиональной группе, классу, роду) порождает два последствия, актуальные для рассматриваемого случая. С одной стороны, каждый японец склонен проявлять патриотизм в рамках интересов своей общности, чем общества в целом. Это приводит к социальным напряжениям, которые ставят под угрозу целостность и устойчивость системы государственного управления. Как показывает исторический опыт, вертикальная сегментация крайне неустойчива и скатывается к насилию в поддержание статус-кво. С другой стороны, культурный плюрализм купирует очаги социального напряжения и даже подавляет их целиком, посредством клиентелистских обязательств внутри культурных сообществ. Этим объясняется преимущественно бесконфликтный характер коммуникативных практик, устойчивое стремление участников к достижению консенсуса.

Коммуникативные практики в «обществе-паутине» складываются на основе неизменных принщипов, задающих «картину мира» (эпистему) и жизненные установки японцев. В основе организации общественной жизни Японии лежит приниип гармонии, обозначаемый термином «ba», вбирающий в себя представления о порядке и гармонии. «Ba» ориентирует на поддержание бесконфликтных отношений, неприятие оппозиционности, игнорирование и подавление мнения меньшинства. С одной стороны, принцип «ba» предписывает воздерживаться от прямой критики, дабы критикуемый «не потерял лица», и предусматривает досудебное разрешение конфликтов, возникающих в сфере управления. С другой стороны, главным механизмом реализации принципа «вa» считается система отношений «оябун - коябун», описываемая в западной науке как отношения «патрон - клиент». В управлении клиентелизм означает абсолютное неприятие индивидуализма в процессе принятия решений и в становлении карьеры.

Центральное место в иерархии смыслов «общества-паутины» занимают отношения «он» (долг благодарности), которые возникают между индивидами, один из которых занимает более высокое положение в социальной иерархии. Причем обязательства возникают в силу самого факта принадлежности к какой-либо социальной группе (семье, предприятию или государству в целом). Высокопоставленные японцы оказывают благодеяние и покровительство нижестоящим, что побуждает последних к ответной признательности. Возникает система «взаимного угодничества» - сеть особых отношений, основанных на оказании услуг, которые опираются на два вида обязательства. Обязательства высшего порядка - «гиму», среди которых: преданность императору, государству и нации, долг перед родителями и предками, обязательства по отношению к своей работе. Эти обязательства не ограничены по времени и объему, не могут быть выполнены полностью, поэтому каждый японец должен исполнять их всю свою жизнь. Повседневные обязательства - «гири» - ограничены по времени и объему и могут быть исполнены в требуемой форме и объеме. $\mathrm{K}$ «гири» относятся обязательства перед лицами, от которых индивид получает благодеяние «он», а также долг по отношению к самому себе (необходимость беречь свое имя и блюсти свое достоинство), предполагающий добросовестное отношение индивида к своим обязанностям (см: Аьюис, 1999: 351-352).

Важнейший принцип, пронизывающий и организующий все пространство коммуникативных практик, - фамилизм. Он означает, что все граждане государства и слу- 
жащие компаний связаны между собой узами взаимных обязательств в своего рода «семью». Быть членом «семьи», как замечает американский эксперт Аж. Элстон, «значит руководствоваться принципом, согласно которому “семья" предполагает взаимную ответственность всех за благополучие каждого» (цит. по: Јо, 1987: 3). Эта ответственность касается всех: рабочего, менеджера, руководителей, поскольку главный критерий членства в семье - участие в исполнении обязательств, а все члены «семьи» в неоплатном долгу перед ней, как сыновья перед матерью.

Таким образом, японский стиль публичного управления основан на приверженности населения групповым, коллективистским и иерархическим нормам и ценностям. В него вошли все компоненты добродетельного поведения (по Конфуцию): человеколюбие ( «жэнь»), чувство долга ( «u»), уважение к старшим ( «сяо»), преданность ( «чжун»), соблюдение норм общественных, внутрисемейных и групповых отношений. По мнению экспертов, приверженность этим принципам позволила сконструировать национальные способы организации общества и методы управления им, воздействующие прежде всего на ментальные коды поведения (Masakazu, 1986).

\section{ПОАИТИЧЕСКИЕ АИСПОЗИЦИИ ЯПОНЦЕВ:}

ПАРТИКУАЯРИЗМ VERSUS УНИВЕРСААИЗМА

Bсе коммуникативные практики Японии в политической сфере включены в особый образец социальных и политических диспозиций, которые в решающей мере определяют эффективность политической системы и ее институтов. Одной из особенностей Японии является отсутствие в массовом сознании понятия «национальное государство» в западном смысле, как иерархически организованной системы власти в масштабах страны, выражающей общезначимые интересы граждан, глубоко осознающих свою принадлежность к нему. В этом случае эксперты для обозначения государства в Японии используют понятие «политически фрагментированное государство», под которым понимается «такое государство, члены которого в большей мере идентифицируют себя с определенной группой, нежели с государством в целом» (Wolferen, 2008: 123).

Именно социальная и культурная сегментация японского общества обусловливает преобладание партикулярных моделей поведения, которые складываются на основе «картины мира» некой группы, в отличие от универсальной, принятой в обществе. Универсальные модели политического взаимодействия складываются на основе общей для всех граждан системы ценностей и картины мира, а их участниками выступают свободные и равные в правах граждане. Напротив, партикулярные модели политического поведения задаются «системой координат» конкретной группы, с которой идентифицирует себя индивид. В Японии партикулярные практики политических взаимодействий существуют в форме клиентелизма (личные обязательства клиента следовать позиции патрона в обмен на покровительство) и примордиальных ориентаций - позиции, обусловленной принадлежностью к роду, клану, религии, семье, жителям города или села, которую ее члены воспринимают как «изначальное».

В Японии диспозиции пассивно-консервативного восприятия политики укоренены в культурных принципах жизни «общества-паутины». Набор традиционных ценностей и обязательств задает паттерны (образцы) поведения управляющего и уnравляемого, определяет их мотивацию, принципы и критерии принятия управленческих решений. Ао сих пор в сфере публичного управления в механизме регулирования 
общественных отношений традиционные предписания, нормы морали и этики имеют решающее значение. В механизме принятия политико-управленческих решений в Японии на общенациональном уровне особенно сильны процедуры и технологии согласования интересов при принятии решений, которые напоминают корпоративные практики принятия решений. В этих условиях доминирует позиция тех сил, которые способны действовать скрытно, игнорируя выборные представительные органы, используя неофициальные, закулисные обсуждения и согласования. Все эти процедуры придают японской модели публичного управления свойства корпоративной демократии.

Распознание специфики партикулярных политических ориентаций в Японии и понимание практик позиционирования возможны в контексте их сопоставления с западными (универсальными) коммуникативными практиками. Аля описания различий в организации политической среды на Западе и Востоке американский политолог $\Lambda$. Пай (1921-2008) использовал метод бинарной оппозиции. Эта исследовательская матрица была создана им в рамках компаративной политологии. Сопоставляя политическое развитие западных и незападных стран, $\Lambda$. Пай связывал их принципиальные различия с культурным кодом, который, по его мнению, определяет практические ориентации и поведение населения в них. Он полагал, что эти различия обусловлены цивилизационными особенностями западного и «незападного» мира. Обобщив эмпирические наблюдения, вслед за М. Вебером, $\Lambda$. Пай создал классический «идеальный тип», способный выразить универсализм коммуникативных практик Запада и уникальность их в «незападных» обществах. По его мнению, именно противопоставление «Запада» «не-Западу», основанное на различии культур, позволяет понять, почему идеи демократии, верховенства прав человека развивались в границах «исторического Запада» и были чужды основам бытия «незападного мира» (Руе, 1965). По мнению $\Lambda$. Пая, политический процесс западного типа прямо противоположен восточному. Он выделяет 17 критериев, по которым различаются политические процессы западного и незападного типа (там же: 16). Используя исследовательскую матрицу $\Lambda$. Пая, можно выделить специфику конструирования политических практик в Японии, исхоАя из доминирующих политических диспозиций.

Во-первых, в противоположность либеральному принципу специализации и разделению политических ролей и функций в Японии сфера политики не отделена от иных сфер общественных и личных отношений, функционально не дифференцирована. Это порождает высокую степень совмещения и взаимозаменяемости политических ролей и функций, доминирование клик в политическом процессе, а не специализированных акторов. Политические партии склоны претендовать на выражение не политических интересов, а мировоззрения и представительство образа жизни населения. Роль институционально-организованных групп интересов, призванных играть функционально специализированные роли в политическом процессе, крайне ограничена.

Во-вторых, в масштабах японского общества отсутствует единая коммуникационная система, что препятствует интеграции участников политического процесса, порождает незначительность и непрочность консенсуса относительно узаконенных целей и средств политического действия. Политический процесс обходится, как правило, без участия политических «брокеров» и носит неконструктивный характер. Социальная сегментация в Японии дополняется резким различием в политических ориентациях поколений, горожан и сельчан, клановой, религиозной и профессиональной принадлежности. Все это вынуждает лидеров придерживаться более опреде- 
ленных взглядов во внешней политике, чем во внутренней. Оппозиционные партии и әлиты, стремящиеся к власти, часто выступают в качестве революционных движений, проводя значительные масштабы рекрутации новых акторов для исполнения политических ролей.

В-третьих, доминирование в политических практиках эмоциональных и символических действий, которые оттесняют на второй план поиски рациональных решений общих проблем и конкретных вопросов. Недифференцированный характер общественности, к которой апеллирует национальное руководство, обусловливает особую роль харизматических лидеров. При әтом руководство политических группировок обладает значительной свободой в определении стратегии и тактики действий, опираясь на подааннический тип политических ориентаций сторонников. В этих условиях принятие политических решений напрямую не связано с интенсивностью и широтой политических дискуссий.

Конечно, любая типология в известной мере нивелирует все богатство политических взаимодействий, акцентируя внимание на различиях в ценностях. В контексте нарастающей глобализации национально-культурная специфика может приобретать откровенно партикулярные формы либо «растворяться» в универсальных институтах. К тому же, несмотря на утверждения о гомогенности западной культуры, она далеко не однородна и состоит из множества субкультур, отражающих цивилизационную и историческую специфику конкретных стран. Эта мультикультурность обусловила многообразие форм политической демократии, которые утвердились в западных обществах. Обычно то, что на Западе называют «современной демократией», оказывается всего лишь одной из ее разновидностей, получившей преимущественное развитие вначале в англосаксонских странах, которые отличаются известной культурной однородностью. Однако в западном мире существуют мульткультурные и многосоставные общества, расколотые на разные этнические, религиозные и культурные группы. В них политический процесс довольно специфичен по сравнению с политическими процессами в культурно однородных обществах. Он представлен моделью «сообщественной демократии» (А. Аейпхарт), в которой политические решения принимаются на основе коалиции әлит, в рамках которых осуществляется артикуляция запросов заинтересованных групп.

Механизм публичного управления в Японии устроен иначе. Он опирается на союз правительственной бюрократии и промышленников, являющийся отражением тенденции сращенности политики и экономики. Как показала практика, стратегия государственного регулирования экономики оказалась не менее эффективной, чем модель рыночной экономики, где государство играет роль «ночного сторожа». В значительной мере именно тандемом бюрократии и бизнеса объясняются впечатляющие успехи роста экономической мощи и национального богатства Японии. Этим же обусловлен успех и других «азиатских тигров»- Южной Кореи, Тайваня, Гонконга, Сингапура. При этом прямое вмешательство государства в экономику в Японии никогда не противопоставляется частному предпринимательству. Более того, чиновники не стремятся полностью подчинить себе частный бизнес и контродировать корпорации, они осуществляют лишь функцию патроната, координируют усилия «капитанов бизнеса», опекают их при продвижении на внешний рынок. В свою очередь бюрократия использует бизнесменов, стремящихся найти новые возможности для расширения своего бизнеса, в качестве «навигаторов» развития национальной экономики, поскольку именно их поиск и инициатива указывают эти направления. 


\section{КАИЕНТЕАИЗМ - БАЗОВАЯ МОАЕАЬ КОММУНИКАЦИИ ВААСТИ И ОБЩЕСТВА В ЯПОНИИ}

Социальная и культурная сегментация японского общества препятствовала формированию универсальной гражданской идентичности, маркером которой выступает национальное государство. Напротив, наличие культурного и социального плюрализма обусловило преобладание примордиальных и клиентелистских форм идентичности. Клиентелизм - это форма личной зависимости, выражающая связь двух лиц патрона и клиента, обладающих неравными возможностями, разным престижем и влиянием, для оказания взаимной поддержки, взаимного обмена услугами. Тем самым клиентелизм является базовой моделью формирования коммуникативных практик практически во всех сферах жизни, и в первую очередь в политике.

Несмотря на наличие институциональных атрибутов государства (монарх, конституция, парламент, правительство, законодательство и т. А.), практически невозможно определить, кто принимает политические решения и кто несет за них ответственность. Хотя по Конституции Японии обязанность принятия решений возлагается на парламент, а реализация их отнесена к компетенции правительства, но на практике рядовые японцы не воспринимают государство как институцию с политической организацией общества, а скорее как иерархически устойчивый набор связей и отношений, обеспечивающих предсказуемые результаты его участникам. В качестве таковых выступают чиновники (бюрократия), политики (парламентарии), бизнес (финансово-промышленные группы), лидеры политических партий (особенно Аиберально-демократической партии Японии). Все вместе они составляют правящий класс Японии, который в традиционных обществах априори выступает инициатором всех начинаний и преобразований. Наряду с высшей элитой существуют менее значимые группы, функционирующие на принципе патроната и обладающие ресурсами властного влияния, - полиция, СМИ, сельскохозяйственные кооперативы и гангстеры. Каждая группа имеет своих «клиентов», интересы которых она представляет и которым покровительствует. Конфигурацию фрагментированной модели власти в Японии К. ван Вольферен сравнивает с «усеченной пирамидой»: «Каждая (группа) наделена дискреционной властью, подрывающей авторитет государства, и ни одна из них не представлена каким-либо центральным руководящим органом, при этом - это усеченная пирамида. Нет верховного института власти, обладающего полномочиями на принятие окончательных решений» (Wolferen, 2008: 20).

Используя культурную традицию «деревенского общества», в основе которого лежит идея иерархического порядка, правящий класс Японии встроил систему патроната в политику для укрепления своей монополии на власть и воспроизводства системы олигархического правления. Господство элиты обеспечивал специфический механизм политического, финансового, административного контроля, уходящий корнями в традиции и ритуалы. Монопольное право правящего класса на принятие политических решений обеспечивало ему контроль за образованием, культурой и СМИ, через которые у населения поддерживались культурные нормы и политические установки на лояльность к власти, конформизм, смирение, покорность. Контролируя общественное мнение и задавая «повестку дня», актуальную новым вызовам, политический класс, тем не менее, укреплял и свои позиции. Так, в период Сакоку - изоляции (1641-1853) военные правители (сегуны) из рода Токугава закрыли страну для иностранцев, ввели запрет на морскую торговлю, которая вела к имущественному расслоению и возвышению торговой буржуазии. В эпоху изоляции были созданы базовые 
принципы консервативно-пассивного политического поведения, положенные в основу политической культуры. В эпоху революции Мэйдзи 1868 г. правящая элита уже не ограничивала проникновение иностранной культуры, но она выбирала их нее те методы и приемы модернизации общества, которые укрепляли ее господство. После поражения во Второй мировой войне (1939-1945), пережив со страной культурный шок, политический класс (под влиянием оккупационных сил США) предложил стратегию модернизации, главным вектором которой стало не самопожертвование и самоотречение, а экономический рост, повышение материального благосостояния граждан при сохранении приоритета общественных обязательств.

Однако правящий класс Японии не однороден, его составляют разные клики (политические, административные, военные, партийные, финансовые), между которыми распределена политическая власть. Аиффузия (распыление) власти между этими кликами исторически была обусловлена клановой, сословной, а затем классовой сегментацией, закреплявшей за каждой из них контроль за теми или иными ресурсами, а позже - через систему патронажа они закрепили свои властные позиции. Сращение политики и экономики, проникновение политики во все сферы жизни общества, тем не менее, не порождали единства внутри политического класса, как и доминирования какой-либо из клик: будь то влиятельные политики или высшие чиновники, как, впрочем, и крупные бизнесмены. На протяжении истории происходил «круговорот» клик, обусловленный преобладанием групп, решающим образом влияющих на процесс принятия решений. Если до середины XX в. таким влиянием обладали гумбаиу (япон. - военная клика) и дзайбачу (финансовая клика), то после поражения во Второй мировой войне и развала японской империи на смену дзайбачу и гумбашу пришла хабачу (партийная клика), а затем - кәйрэиу (крупные корпоративные конгломераты и холдинги, связанные друг с другом в экономический кластер).

Ао окончания Второй мировой войны традиционная имперская экономика строилась на дзайбаиу - финансовых и промышленных концернах, активы которых находятся в руках одной влиятельной группировки предпринимателей. Азайбацу представляли собой конгломерат разнообразных предприятий, объединенных под контролем головной семейной компании. Вертикаль власти в дзайбацу, имевшая у своей верхушки одну семью, создавала эффективные механизм административного и финансового контроля, на который опирались политические и военные клики. Крупнейшие дзайбацу ( «Мицуи», «Мицубиси», «Сумитомо», «Тошиба», «Ясуда») контролировали основные отрасли экономики, способствуя милитаризации Японии, имели большое влияние в довоенной политической системе, выступали как вдохновители внешней агрессии (см.: Карасев, 2008: Электронный ресурс).

После Второй мировой войны в Японии оккупационные силы США провели на островах реформы, направленные на преобразование дзайбацу. Подконтрольные семьям активы были конфискованы; главы конгломератов ликвидированы; объединенные руководства картелей, неотъемлемая часть старой системы координации всех компаний, были объявлены вне закона. По плану SCAP (от англ. Supreme Commander Allied Powers - Главнокомандующий силами союзников) основные на тот момент дзайбацу - «Асано», «Фурукава», «Накадзима», «Ниссан», «Номура» и «Окура» - подлежали ликвидации в 1946 г. Оккупационные власти упразднили 245 головных финансовых холдингов, запретили перекрестное кредитование и конфисковали имущество руководящих семей (см.: Кошкин, 2009: Электронный ресурс). Однако полного уничтожения дзайбацу союзническими реформами не было достиг- 
нуто, отчасти благодаря тому, что это противоречило настроениям в японском обществе. Население сочло дзайбацу выгодными для страны, а общественное мнение Японии было против их упразднения. Стала иной и политика Оккупационных сил в отношении Японии, которая состояла в выстраивании стратегического партнерства в противовес союзу СССР и КНР. Оставшиеся дзайбацу были реорганизованы на принципах современных американских и западноевропейских монополий - со свободной куплей-продажей акций, широким привлечением внешнего капитала. В итоге практически все дзайбацу были реформированы в кэйрэцу и в форме кәйрэцу существуют до сих пор, контролируя существенную часть экономики Японии. Главное отличие кәйрэцу от дзайбацу состоит в том, что если в дзайбацу власть в концерне при-надлежала одной семье, то в кэйрэцу вертикаль власти была заменена горизонтальными партнерскими и координационными отношениями между ассоциациями. Как правило, кэйрэцу группируются вокруг мощного банка, который обеспечивает финансирование всех компаний группы и фактически исключает возможность их враждебного поглощения другими участниками рынка. Наиболее типичными примерами кэйрэцу являются, в частности, широко известные группы - Mitsubishi, Mitsui, Sumitomo, Fuyo.

\section{КАНААЫ АРТИКУАЯЦИИ ИНТЕРЕСОВ \\ В МЕХАНИЗМЕ ПУБАИЧНОГО УПРАВАЕНИЯ ЯПОНИИ}

Поскольку японское общество не может быть отнесено к современным (т. е. индивидуалистическим) обществам, постольку оно использует бинарную систему политических и социальных коммуникаций, в которой универсальные и локальные институты дополняют друг друга, при доминировании национальных практик. Формально в Японии существуют легальные каналы коммуникации общества и власти в лице парламента, партий, выборов, СМИ, оппозиции. Однако их встраивание в политическое пространство Японии произошло в рамках культурной традиции «коллективного авторитаризма», которая существенно изменила их первоначальный смысл.

Наряду с легальными каналами репрезентации интересов групп и общностей существует традиционная японская система вертикального представительства политических интересов, которая опирается на принцип группизма, где клики и иные неформальные организации для укрепления своего господства используют преимущественно латентные каналы коммуникации и апеллируют к политическим ориентациям своих сторонников на авторитарность, почтительность, секретность, замкнутость, доминирующие в японском менталитете. Традиционная система представительства интересов в Японии ориентирована на достижение максимальной стабильности. Попытки упразднить латентные практики политической коммуникации, начатые в 1945 г.

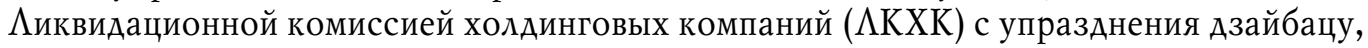
изъятия авуаров и активов, закончились неудачей. Вместо «финансовых клик», управляемых узкой группой лиц, возникли кэйрэиу - «большие современные группировки предпринимателей» (по определению А. А. Метро и К. А. Уоррена) с широкой и автономной членской базой (Карасев, 2008: Электронный ресурс). Иначе говоря, крушение конкретных институтов не означало замены принципов и стереотипов политического поведения.

Исторически специфика функционального представительства в Японии состоит в том, что большинство организаций функциональных групп (бизнеса, наемных работников, лиц свободных профессий) созданы представителями чиновничьего аппа- 
рата, а не самими группами. В этом состоит источник их могущества и влияния. Аействительно, в период формирования, крупнейших федераций бизнеса, включая Кэйданрэн, ими руководили чиновники, которые отвечали за мобилизацию экономических ресурсов во время Второй мировой войны, и обюрократившиеся руководители картелей военной поры. В этом кроется одна из главных причин успешного партнерства между бюрократией и бизнесом.

Основным неформальным каналом продвижения интересов функциональных групп является дзоку - группа депутатов парламента, имеющих сильное влияние и пользующихся непререкаемым авторитетом в пределах какой-либо сферы государственного управления. Азоку лоббируют интересы функциональных групп в парламенте. Как правило, «верхушку» этой неформальной группы составляют бывшие министры, в руководство входят депутаты - бывшие парламентские замминистра, председатели профильных парламентских ассоциаций и соответствующих отраслевых комитетов (Иванов, 2009: Электронный ресурс). Японский эксперт Итакаги Хидэнори

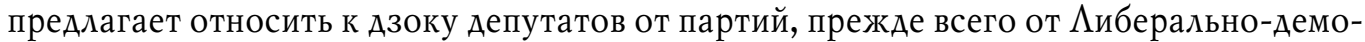
кратической партии Японии (МАПЯ) и руководителей высшего и среднего уровня (см.: Карасев, 2008: Электронный ресурс). Однако независимо от занимаемых постов в парламенте или партийных органах (политических, управленческих, технических), члены дзоку превращаются в реальную силу на входе в эту пирамидальную структуру власти, поскольку здесь на них замыкаются уже важнейшие политические решения и финансовые интересы.

Аругим важным латентным каналом продвижения интересов являются кэйрэиу неформальные группировки, образующие новую систему представительства интересов, построенную на личных связях и теневом сотрудничестве. Аатентные практики представительства интересов новых корпоративных предприятий по-прежнему актуальны и интегрированы в модель «японской демократии» с одной лишь поправкой: «Главное отличие кэйрэцу от дзайбацу - замена вертикального подчинения через общий холдинг - на горизонтальное, через скрытую систему взаимных финансовых обязательств» (Wolferen, 2008: 12).

Более того, сращивание японского бизнеса с правительственной бюрократией в современной Японии приобрело новые формы латентных практик. Аля получения привилегий и влияния на прохождение законов в парламенте определенные группы бизнесменов и отдельные крупные корпорации занимаются систематическим подкупом членов $\Lambda А П$. Однако это не позволяет существенно влиять на политику в целом, тем более что неформальный контроль бюрократии за бизнесом простирается очень далеко.

Патронажная модель коммуникации бизнеса и власти в Японии привела к возникновению еще одного латентного канала представительства интересов корпораций зайкан - широкого круга функционеров бизнеса, представляющих могущественные корпорации. Зайкан - влиятельная группа руководителей корпораций внутри правящего класса Японии, которую ошибочно отождествляют с государственной властью. У стороннего наблюдателя, незнакомого с реалиями Японии, возникает впечатление, что именно руководители корпораций оказывают решающее влияние на принятие политических решений. В этом случае получается, что чиновники и партийные функционеры $\Lambda$ П выступают как доверенные лица зайкан. Однако это впечатление ошибочно. Известный эксперт по Японии К. Ван Вольферен пишет: «Верно, что японские корпорации действуют в чрезвычайно благоприятной политической среде, но лишь 
постольку, поскольку промышленная экспансия остается целью национального развития в глазах чиновников экономических ведомств и $\Lambda А П$, и многие из применяемых методов рассматриваются как сами собой разумеющиеся. Но это не превращает президентов и председателей промышленных корпораций в тайных правителей Японии» (Wolferen, 2008: 34). Ааже в экономической сфере зайкан слишком зависит от министерств, поскольку нуждается в защите своих предприятий от иностранной конкуренции на внутреннем рынке, а также в руководстве и координации при продвижении новых видов производств на иностранный рынок.

Наряду с латентными практиками коммуникации в современной Японии существуют институциональные каналы. Так, артикуляцию интересов японского бизнеса и наемных работников осуществляют организации функиионального представительства: 1) JBF - Nippon Keidanren, Японская федерация ассоциаций бизнеса; 2) JBA Ассоциация японских банков; 3) JILAF - Японский международный фонд труда; 4) NCTU - Японская национальная конфедерация профсоюзов, 5) NFSBA - Национальная федерация ассоциаций малого бизнеса Японии: 6) General Union - головная организация профсоюзов; 7) JAEF - Nikkeiren, Федерация ассоциаций работодателей Японии; 8) JCTU - Rengo, Японская конфедерация профсоюзов; 9) NTUC - Zen Rokyo, Национальный совет профсоюзов; 10) NFTU - Zenroren, Национальная федерация профсоюзов; 11) JCCI - Торгово-промышленная палата Японии (см.: Карасев, 2008: Электронный ресурс).

Подобная функциональная специализация групп интересов распыляет их возможности влиять на власть. Как следствие, стремление к консолидации, которое прежде всего обнаружили профсоюзы: 12 июня 1991 г. была учреждена головная организация - General Union, объединившая три крупные ассоциации наемного труда JCTU, NTUC и NFTU, а также несколько мелких профсоюзов. В 2002 г. произошла консолидация интересов бизнеса: слияние Nikkeiren и Keidanren на базе последней, что привело к уменьшению специализации головной ассоциации предпринимателей $(\mathrm{JBF})$. Эти слияния говорят об известной консолидации интересов бизнеса по двум направлениям: предприниматели плюс работодатели и профсоюзы, - что воспроизводит традиционный раскол труд - капитал, но в несколько приглушенной форме (Грейсон, О’Аелл, 1991).

Аругой полюс коммуникации - «власть и общество». Подданический тип политической культуры определил формы участия населения в политике. При этом участие населения (главным образом разные формы поддержки правительства) задается правящим классом сверху посредством механизма мобилизации и контроля.

Первая модель политического участия - патронажно-клиентарная, связанная с насаждением почтительного отношения населения к власти. Через систему ценностей культура задает мотивацию поведения управляющего и управляемого, обеспечивает легитимацию принятых управленческих решений, способствует регуляции отношений внутри управляющей системы. В японской модели управления определяющее значение имеют такие ценности, как иерархия, патернализм в отношениях между государством и личностью, долг, обязанность, приверженность группе и подчинение ее интересам (группизм), ориентация на консенсус, преданность корпорации, фамилизм. Ценностные нормы обусловливают цели публичного управления в Японии, в соответствии с которыми оно выстроено: ориентация на стабильность и минимизацию риска, конфликтности, достижение гармонии в обществе. Строгая иерархия моральных и социальных обязательств по вертикали и по горизонтали обусловлива- 
ет использование неформальных механизмов принятия решений в духе патернализма в случае возникновения конфликта с учетом половозрастной дифференциации, социальной и профессиональной иерархии. Японская патерналистская система управления, ориентированная на взаимозависимость всех и каждого, прямо противоположна западной модели управления, призванной реализовать запросы граждан с индивидуалистическими ценностями, установками и ориентациями. Следовательно, уникальность национальной культуры Японии обусловила господство традиционных стереотипов политического поведения японцев и определила своеобразие коммуникативных практик «общества-паутины» в сфере политики.

Вторая модель политического участия - инвестищионная. Она является более прагматичной и состоит в том, что население на выборах отдает свои голоса в обмен на ожидаемые блага, которые обещают кандидаты от местных культурных, клановых сообществ. Следует иметь в виду, что в Японии отсутствует коммуникация, основанная на принципе свободы выбора, свойственная западным демократиям. Будучи патерналистским, государство в Японии не является результатом договора власти с обществом, а политический курс не есть следствие свободного выбора населения, предполагающего согласование интересов разных групп. Отчаянные попытки Японии преуспеть в технологическом соревновании с западными странами явили миру «японское чудо» с самой высокой продолжительностью жизни и самым высоким душевым потреблением ВНП. Оборотной стороной этого успеха являлось энергичное утверждение национальной самобытности, чувства превосходства над другими нациями, подавление индивидуальности, невозможность самореализации личности, низкий уровень жизни населения среди развитых стран.

\section{ИНВАЗИЯ УНИВЕРСААЬНЫХ ПОАИТИЧЕСКИХ ПРАКТИК В ЯПОНИИ: МЕХАНИЗМ ОТБОРА И ИМПАЕМЕНТАЦИИ}

Сохраняя многие черты традиционализма и патриархальности, современное японское общество с трудом принимает новации, а если и заимствует новшества, то усваивает их в национально-культурных формах, подстраивая их под собственные системы и структуры (феномен японского конформизма). Это касается и сферы политического управления.

Аоминирующие пассивно-консервативные диспозиции и паттерны политического поведения японцев (дух гармонии и сотрудничества, учтивости и смирения, благодарности и справедливости) трансформируют действие универсальных институтов и практик демократического правления, которые совершенно иначе работают в незападной культурной среде. При этом политическое управление в Японии строится не на организационной иерархии, а на неформальных, латентных практиках коммуникации «руководителя и подчиненного». Аостаточно обратиться к анализу ряда принципов и институтов демократического правления, содержание и назначение которых трансформировала культурная среда Японии.

Государство - провайдер обшественных интересов. Западная установка, что государство - результат общественного договора и механизм выражения общезначимых потребностей, отвергается. Само государство ассоциируется с бюрократией, группами чиновниками, принимающих важнейшие решения и реализующих их. В Японии государство - синоним бюрократии. Так, на практике при принятии решений по текущим вопросам государственного управления высшие чиновники из министерств финансов, международной торговли и промышленности, строительства, поч- 
ты и телекоммуникаций Японии обладают гораздо большей властью, чем та, которой они формально наделены. Кроме того, все решения, принимаемые на заседании кабинета министров, обычно представляют собой процедуру утверждения проекта, ранее согласованного заместителями министра (высшими чиновниками в каждом министерстве) на их собственном совместном заседании. Поэтому заседания кабинета превращаются, как правило, в церемониальное мероприятие принятия проекта (Анисимцев, 2004).

Существенно вмешательство чиновников в жизнь общества и экономику посредством использования как формальных, так и неформальных полномочий. Причем неформальные полномочия позволяют им осуществлять значительно больший контроль над теми сферами общественной жизни, за которые они несут ответственность. Аегальные полномочия чиновников в Японии значительные: они контролируют, регулируют экономику, обеспечивают стимулы для ее развития, разрабатывают проекты законов, которые всегда утверждает парламент. Принятые законы и инструкции к ним чиновники, как правило, используют для достижения собственных личных целей.

Bыюоры и многопартийность. Западные практики говорят о том, что всеобщие выборы - важнейший канал коммуникации власти и общества, состоящий в свободном волеизъявлении народа, определяющем состав законодательного органа. На Западе любая партия стремится в первую очередь к достижению широкой поддержки со стороны избирателей посредством формулирования актуальной «повестки дня» или программы действий в национальном масштабе. В Японии выборы как институт демократии оказываются фикцией. На практике политическая конкуренция и свобода выбора в Японии отсутствуют в силу политической монополии $\Lambda$ П. На протяжении

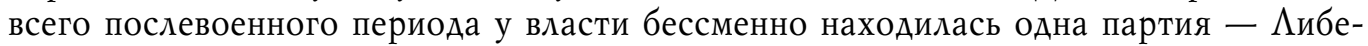
рально-демократическая партия. Политическая монополия $\Lambda$ П позволяет квалифицировать японскую политическую систему как однопартийную. На парламентских выборах $\Lambda$ П поддержку избирателей обеспечивает главным образом за счет использования административного ресурса (связи с правительственными кругами, от которых зависит значительная часть поступлений в местные бюджеты), подкупа избирателей, всевозможных махинаций. За $\Lambda$ чП чаще всего голосуют жители сельских районов, которые испытывают наибольшую зависимость от финансовой поддержки центра. Представители высшей бюрократии в рядах $\Lambda$ П гарантируют им эту поддержку в обмен на голоса.

Кроме подкупа избирателей, $\Lambda$ П использует махинации в избирательной географии - неравенство в численности избирателей в избирательных округах. Число мандатов от сельских округов оказывается непропорционально большим по сравнению с численностью их населения: голос одного сельского жителя весит столько же, сколько голоса трех горожан. Основной акцент в избирательной кампании $\Lambda$ п делает на обеспечение тотальной явки на избирательные участки сельских жителей. Как отмечал известный эксперт, «когда $\Lambda$ ПП завоевывает вдвое больше голосов, чем Японская социалистическая партия (ЯСП), это не значит, что ее идеи, касающиеся политики благосостояния, оцениваются вдвое выше. Это означает только то, что ее деньги вдвое более весомы, чем одни лишь мнения ЯСП. Все, что отличает парламентариев $\Lambda А П$ от других японцев, - это личные привилегии и способность передавать государственным чиновникам просьбы о покровительстве от своих лоббирующих сторонников» (цит. по: Wolferen, 2008: 31). 
Приниип ответственного правительства. В парламентской монархии принцип правительства, ответственного перед парламентом, остается декларацией в силу доминирования в механизме управления органов исполнительной власти и высших чиновников. Победившая на парламентских выборах партия не только формирует правительство, но, имея большинство в парламенте, контролирует его. Кабинет министров, осуществляющий исполнительную власть в Японии, состоит из министров, которые не руководят работой министерств, во главе которых они поставлены. Этим занимается группа высших чиновников министерства. Обусловлено это тем, что министры являются политическими назначенцами - представителями партии, победившей на парламентских выборах. Не будучи специалистами в сфере публичного управления, они большую часть времени проводят в дискуссиях на сессиях парламента. Частые перестановки в кабинете не позволяют министрам глубоко вникнуть в суть работы министерства, чтобы разумно распоряжаться огромными финансовыми и административными ресурсами, эффективно контролировать бюрократический аппарат своих ведомств. Карьерная бюрократия министерств блокирует все попытки министров воспользоваться своими властными полномочиями, которыми они формально наделены.

Если внутри страны правительство проводит интервенционистскую политику, то во внешнеэкономической сфере оно ведет себя сдержанно. Во внешней торговле в силу известных достижений японцы «страдают комплексом превосходства» над другими и не хотят идти на уступки партнерам, если те не прибегают к судебным санкциям. Однако японская экономика нуждается во внешних рынках для экспорта, чтобы развиваться дальше, и правительство активно патронирует бизнес за рубежом. При этом политики и чиновники привычно предпочитают изоляцию, которая сформировала их социальные практики, чтобы не отвлекаться на международные проблемы.

\section{ЗАКАЮЧЕНИЕ}

Таким образом, структура институтов публичного управления в Японии аналогична парламентским моделям, распространенным на Западе, но адаптирована к местной культурной среде. По этой причине современная система политической коммуникации Японии представляет собой синтез традиционных начал и институциональных новаций. Благодаря развитой культурной традиции и ориентации элит на реализацию национальных интересов система публичного управления Японии чрезвычайно восприимчива к внешним изменениям и способна трансформироваться. Включение западных институтов, технологий и практик в японское общество можно рассматривать как комплекс неполноценности. Однако японцы относятся к этому весьма прагматично: зачем тратить деньги на то, что уже изобретено, что повысит качество жизни? В целях лучшего восприятия и адаптации к повседневной жизни все новации были облечены в национально-культурные формы и преследовали одну цель - процветание нации, достижение ее могущества. Выработанный элитой механизм аккультурации западных политических институтов и практик позволял сохранить привычки, верования, духовные основы жизни, при этом с помощью новаций успешно отвечать на вызовы времени.

Современные представительные западные модели демократии в XXI в. столкнулись с вызовами, которые позволяют говорить о кризисе западной «горизонтальной демократии». Западная демократия основана на тезисе о равных возможностях всех граждан в выражении своего мнения посредством институтов СМИ, выборов, заин- 
тересованных групп. В противовес западной плюралистической модели представительства интересов в Японии создана собственная версия «демократии», которую условно можно назвать «вертикальной демократией». Японская «вертикальная демократия» основана на группизме, формируется элитами сверху вниз посредством патронажно-клиентарных связей. Вертикальная коммуникация власти и общества задается правящим классом и опирается на культурную традицию «деревенского общества», позволяющую включить индивидуальные интересы в четко определенные общие цели. Можно предположить, что в условиях нарастающего многообразия интересов в обществах XXI в. гармонизация интересов и процветание возможны благодаря синтезу универсальных и локальных политических практик артикуляции интересов.

\section{СПИСОК АИТЕРАТУРЫ}

Анисимцев, Н. В. (2004) Правовая эволюция государственного строя Японии: внешнеполитические следствия (прогноз) // Известия Восточного ин-та. № 8. С. 74-83.

Бьюкенен, Аж. (1994) Конституция экономической политики [Нобелевская лекция 1986 г.] // Вопросы экономики. № 6. С. 105-111.

Грейсон, Аж. К. мл., О’Аелл, К. (1991) Американский менеджмент на пороге XXI века. М. : Экономика. 320 с.

Иванов, А. (2009) Конец японской «партии власти»? // Интелрос. URL: http://www.intelros.ru/pdf/Rus_Jornal/38/14.pdf (дата обращения: 29.03.2014).

Карасев, М. (2008) Системы представительства интересов бизнеса в Японии [Электронный ресурс] // Политком.Py. URL: http://politcom.ru/print.php?id=6170 (дата обращения: 29.03.2014).

Кошкин, А. (2009) Почему в Японии кардинально изменилась власть? [Электронный ресурс]// Newsland. URL: http://newsland.com/ news/ detail/id/421936/ (дата обращения: 29.03.2014).

Аьюис, Р. (1999) Аеловые культуры в международном бизнесе: от столкновения к взаимопониманию : пер. с англ. М. : Аело. 439 с.

Фуко, М. (2002) Интеллектуалы и власть : избр. полит. ст., выступл. и интервью : пер. с фр. М. : Праксис. 390 с.

Jo, Moon N. (1987) Japanese Traditional Valúes and Industrialization // International Social Science Review. Vol. 62. № 1. P. 3-13.

Masakazu, Y. (1986) Pluralism in der Kultur. Japan in der Westen. Franfurt a. M. : Campus Verlag. 457 р. (На нем. яз.).

Pye, L. (1965) Political Culture and Political Development // Pye, L., Verba, S. Political Culture and Political Development. Princeton : Princeton University Press. 241 p. P. 3-26.

Wolferen, K. Van. (2008) The Enigma of Japanese Power: People and Politics in a Stateless Nation. L. : Macmillan London ltd. 412 p.

Аата поступления: 11.04.2016 2.

MODELS OF COMMUNICATION BETWEEN AUTHORITIES

AND SOCIETY IN THE MECHANISM OF PUBLIC ADMINISTRATION

IN CONTEMPORARY JAPAN

R. T. MUKHAEV

(MOSCOW UNIVERSITY FOR THE HUMANITIES)

The article examines the cognitive foundations of communicative practices in public administration of non-Western societies (specifically, the case of Japan).

We have analyzed both legal and shadow channels that various interest groups use to influence how the institutes of public authorities distribute the 'public benefit'. All communicative practices in 
public services are included in a special model of social and political dispositions which largely define the efficiency of political system and its institutes in different countries. These dispositions and patterns of behavior explain why universal institutes and practices of democratic governance work differently in different societies.

The structure of institutes of public administration in Japan is analogous to the Western parliamentary models, albeit adapted to the local cultural environment. This is why political communication in contemporary Japan works as a synthesis of tradition and institutional innovations. Advanced culture and the elites' focus on national interests made the Japanese system of public management extremely sensitive to external change and capable of transforming. While declaring continuity with religious, philosophical and ethical tradition, the Japanese always remain flexible and ready to adopt foreign practices if they are deemed useful for the country's development and enhance the power of the authorities. To help the society better understand them and adopt them in everyday life, these innovations are shaped in the forms of national culture. Adopted in this way, foreign practices appear as traditional Japanese, which meant that the very religious and philosophic tradition is "Westernized" and renovated to stand the challenges of new times. In this sense, the Japanese system of public administration is indeed innovative, as it keeps being perfected by drawing upon institutions and procedures of Western (both continental and Anglo-American) public administration

Keywords: power; policy, interest groups; political practices; democracy; Japan; political culture of Japan

\section{REFERENCES}

Anisimtsev, N. V. (2004) Pravovaia evoliutsiia gosudarstvennogo stroia Iaponii: vneshnepoliticheskie sledstviia (prognoz) [Legal evolution of the political system of Japan: foreign policy implications (an estimation)]. Izvestiia Vostocbnogo instituta, no. 8, pp. 74-83. (In Russ.).

Buchanan, J. M., Jr.. (1994) Konstitutsiia ekonomicheskoi politiki. [Nobelevskaia lektsiia 1986 g.] [The Constitution of Economic Policy. [Nobel lecture 1986]]. Voprosy ekonomiki, no. 6, pp. 105-111. (In Russ.).

Grayson, C. J., Jr., and O’Dell, C. (1991) Amerikanskii menedzment na poroge 21 veka [American Business: A Two-Minute Warning - Ten Changes Managers Must Make to Survive]. Moscow, Ekonomika Publ. 320 p. (In Russ.).

Ivanov, A. (2009) Konets iaponskoi «partii vlasti»? [The end of the Japanese "party of power"?] Intelros [online] Available at: http://www.intelros.ru/pdf/Rus_Jornal/38/14.pdf (accessed 29.03.2014). (In Russ.).

Karasev, M. (2008) Sistemy predstavitel'stva interesov biznesa v Iaponii [The systems of representation of business interests in Japan] Nomad. Kocbevnik [online] Available at: http://www.nomad.su/ ?a=3-200805150504 (accessed 29.03.2014). (In Russ.).

Koshkin, A. (2009) Pochemu v Iaponii kardinal'no izmenilas' vlast'? [Why a fundamental change in the system of power in Japan?]. Newsland. [online] Available at: http://newsland.com/news/detail/ $\mathrm{id} / 421936 /$ (accessed 29.03.2014). (In Russ.).

Lewis, R. D. (1999) Delovye kul'tury v mezhdunarodnom biznese: ot stolknoveniia k vzaimoponimaniiu [When Cultures Collide: Managing successfully across cultures]. Moscow, Delo Publ. 439 p. (In Russ.).

Foucault, M. (2002) Vlast' i znanie [Power and knowledge]. In: Foucault, M. Intellektualy i vlast': Izbrannye politicheskie stat' $i$, vystupleniia $i$ interv' $i u$. [Intellectuals and power: Selected political papers, speeches and interviews]. Moscow, Praxis Publ. 390 p. (In Russ.).

Jo, M. N. (1987) Japanese traditional valúes and industrialization. International Social Science Review, vol. 62, no. 1, pp. 3-13.

Masakazu, Y. (1986) Pluralism in der Kultur. Japan in der Westen. Franfurt a. M.: Campus Verlag. 467 p. (In Germ.).

Pye, L. (1965) Political Culture and Political Development. In: Pye L. and Verba S. Political Culture and Political Development. Princeton: Princeton Unyversity Press. 241 p. Pp. 3-26. 
Wolferen, K. Van. (2008) The Enigma of Japanese Power: People and Politics in a Stateless Nation. London, Macmillan London ltd. 412 p.

Submission date: 11.04.2016.

Мухаев Рашид Тазитдинович - доктор политических наук, профессор кафедры теории рекламы и массовых коммуникаций Московского гуманитарного университета. Адрес: 111395, Россия, г. Москва, ул. Юности, д. 5. корп. 3. Тел.: +7 (499) 374-78-45. Эл. aдpec: muhaev_r@mail.ru

Mukhaev Rashid Tazitdinovich, Doctor of Political Science, Professor, Department of theory of advertising and mass communication, Moscow University for the Humanities. Postal address: Bldg. 3, 5 Yunosti St., Moscow, Russian Federation 111395. Tel.: +7 (499) 374-78-45. E-mail: muhaev_r @mail.ru 